Annette Albrecht

\title{
Die deliktische Haftung für fremdes Verhalten im französischen und deutschen Recht
}

Eine rechtsvergleichende Untersuchung unter besonderer Berücksichtigung der Blieck-Rechtsprechung der Cour de cassation

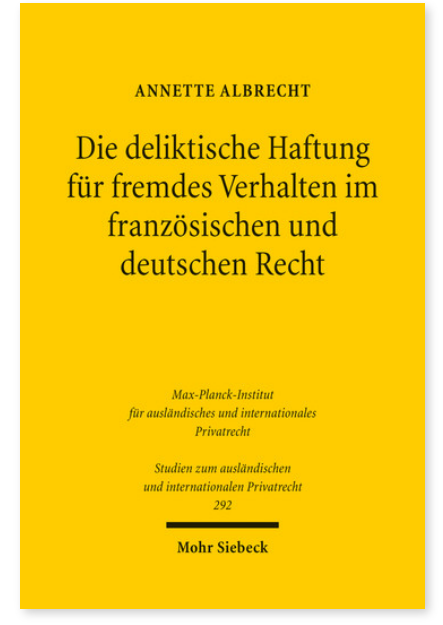

2013. XVIII, 175 Seiten. StudIPR 292

ISBN 978-3-16-152693-0

DOI 10.1628/978-3-16-152693-0

eBook PDF $69,00 €$

ISBN 978-3-16-152669-5

fadengeheftete Broschur 69,00€
Unter welchen Voraussetzungen muss eine Person für das schädigende Verhalten einer anderen Person gegenüber dem Geschädigten einstehen? Es werden zwei Fallgruppen näher beleuchtet: Die Haftung von Betreuungspersonen für Kinder und Behinderte und die Haftung von Organisationen für ihre Mitglieder. Während in Frankreich seit dem Blieck-Urteil aus dem Jahr 1991 die Haftung durch die Cour de cassation als verschuldensunabhängige, objektive Einstandspflicht ausgestaltet ist, sieht das deutsche Recht eine Haftung für vermutetes Verschulden vor. Annette Albrecht arbeitet die Rechtsprechung in beiden Rechtsordnungen auf und vergleicht diese. Dabei beleuchtet sie auch Reformvorhaben in beiden Ländern und behandelt die bisherigen Bemühungen um ein einheitliches europäisches Haftungsrecht. Sie schließt mit einer dogmatischen und rechtspolitischen Bewertung der vorhandenen Lösungsansätze, die auch die Versicherbarkeit von Schäden berücksichtigt.

Annette Albrecht Geboren 1980; Studium der Rechtswissenschaft in Freiburg und Grenoble; 2006-09 Koordinatorin des Auslandsbüros der Rechtswissenschaftlichen Fakultät Freiburg; 2011 Zweite Juristische Staatsprüfung in Hamburg; 2012 Promotion; seit 2012 Richterin auf Probe am Landgericht Offenburg.

Jetzt bestellen:

https://mohrsiebeck.com/buch/die-deliktische-haftung-fuer-fremdes-verhalten-im-franzoesischen-und-deutschen-recht9783161526930?no_cache=1

order@mohrsiebeck.com

Telefon: +49 (0)7071-923-17

Telefax: +49 (0)7071-51104 